\title{
DANZA GALLEGA EN HONOR DE LA LUNA
}

\author{
Por \\ FINA M. ANTÓN y M. MANDIANES
}

Como en cualquier cultura indoeuropea, la importancia de la luna en la cultura gallega tradicional es grande. El trabajo de divide en tres partes: 1) residencia de las almas, 2) las cuarentenas y 3) una danza en honor de la luna.

\section{RESIDENCIA DE LAS ALMAS}

La luna está presente y es determinante en cada uno de los momentos de la vida del individuo, especialmente en cada uno de los ritos de paso: concepción, nacimiento, casamiento y muerte. Los padres que deseaban tener un niño, mantenían relaciones sexuales durante la fase creciente de la luna, y los que deseaban tener una niña, las mantenían durante la fase menguante ${ }^{1}$.

La noche del 30 de abril al 1 de mayo ${ }^{2}$, las brujas repartían entre los vecinos de los pueblos las moscas y el agua, que adquiría virtudes preventivas y curativas especiales que le comunicaban los habitantes del aspecto oculto del mundo al salir de su residencia habitual con la última fase de la luna de abril, la luna roja, y el corte de las primeras hierbas que

1 J. Taboada, «Folklore astronómico y metereológico de la comarca de Monterrey», en RDTP V (1949),110-137; A. Fraguas, Galicia insólita (Libregal, Coruña 1973), pp. 27-57; J. Ramón y Fernandez Oxea, «El folklore sobre los niños en Cariño (Coruña)», RDTP, I(1944-45), 158-161; V. Risco, «Sobre la vida de los niños en la aldea gallega», en RDTP, XIII (1957), 227-253.

"CUADERNOS DE ESTUDIOS GALLEGOS", Tomo XLV, Fascículo 110, Santiago 1998. 
les permitía soltar amarras. Por miedo a que estos acontecimientos causaran malos entendimientos y dificultaran las relaciones, los gallegos suspendían los casamientos durante el mes de mayo. Empezaban a casarse otra vez en junio cuando, como fruto de las rogativas y la fiesta de San Pedro Mártir, el 29 de abril, todos los habitantes del mundo convivían en paz.

Las aguas están habitadas por una serie de seres; Martín Dumiense habla de las Ninfas; pero eso no es más que una romanización de la realidad. Los gallegos hablan de anas, xanas, xigantes, todos nombres femeninos derivados en gran parte de la raíz celta anaon que designa a los antepasados. Los bosques, las rocas, el mar, las fuentes y los ríos estaban poblados para los celtas como aún lo están hoy para los campesinos. Los seres que producen y controlan la lluvia, y otros, habitan en el aire. Desde los ríos, las ánimas suben por una de las cepas del arco iris a la luna, desde donde vienen, luego, en forma de abeja ${ }^{3}$.

Las ánimas, que vienen de la luna en forma de abeja, son, para los gallegos, los antepasados integrados en la vida cotidiana; andan de noche por el centro de los caminos vestidas con camisas blancas, como albas de cura, que les llegan hasta los pies, y siempre van descalzas; «nadie vio

${ }^{2}$ A. Vicenti, «La última noche de abril», in La ilustración gallega y asturiana, I, 24(1879), 88-89; M. Murguía, Galicia (Barcelona, 1888), pp. 181-184J. Taboada, «Moros y cristianos en Tierras de Laza (Orense)», Rev. de Dialectología y Populares, XI (1955), pp. 334-352.

${ }^{3}$ De correcttione rusticorum, n. 8; Cfr. G. Dumézil, Mythe et époée, III: Histoires romaines (Ed. Gallimard, Paris 1981), 39-89 La mujer encinta no puede comer frutos de mar, tales como el pulpo, ni atravesar un río porque correría el riesgo de perder el embarazo; por el contrario, la mujer que lo perdía habitualmente debía hacerlo bautizar, a las doce de la noche, en una encrucijada formada por un puente y un río cuando aun lo llevaba en su vientre porque las aguas de la placenta hacen pensar en las aguas del mar y del río. Los ríos, en principio, son siempre límites entre parroquias, unidad fundamental en el mundo simbólico gallego. Cfr. C. Alberto, «Un aspecto do culto dos rios na Lusitania», en Douro Litoral, $8^{\text {a }}$ serie, IX (1958), 873-887; F. Bouza Brey, «Los mitos del agua en el noroeste hispano», en Etnografía..., op. cit., p. 219-239; Lima Carreiro, «A agua na lenda e no folklore», en Douro Litoral, $4^{\text {a }}$ serie, V-VI (1951), 31; F. López Cuevillas, «O culto das fontes no noroeste hispánico», en Traballos da sociedade portuguesa de antropologia e etnografia, fasc. 2 y 3, vol. VIII; Pereira, A., «Bautismo intrauterino en cinco puentes del Condado de Salvatierra», en Actas del II Coloquio galaico-minhoto (Santiago 1984 397-404).

"CUADERNOS DE ESTUDIOS GALLEGOS", Tomo XLV, Fascículo 110, Santiago 1998. 
jamás un ánima calzada». A veces se aparece alguna sola pero, por lo general, se aparecen muchas juntas, como en procesión. Delante de ellas va un vivo con la cruz que sigue el itinerario que ellas le han marcado. A los que encuentran en la encrucijada los invitan a comer ${ }^{4}$.

En las doctrinas maniqueas y gnósticas, la luna es considerada como bomba de almas: durante el período creciente las almas de los muertos se elevan hasta ella, que las aspira; luego, cuando mengua, son enviadas otra vez. Una lunación corresponde al ciclo femenino; la experiencia ha permitido situar hacia el día 13 ó 14 del ciclo lunar los momentos más fecundos. Las lunas nuevas corresponden a las reglas de la mujer y las lunas llenas a los de fecundidad. Hay que matar los animales entre lunas porque la luna nueva cría bichos en la carne y la menguante la hace menguar. Todo lo que aumenta sobre la tierra, como el maíz, el trigo, hay que sembrarlo en luna nueva y, por el contrario, todo lo que aumenta debajo de la tierra hay que sembrarlo en luna vieja. La luna creciente favorece la multiplicación de los granos y la menguante los volúmenes. Las patatas sembradas en luna nueva sólo aumentarían en rama y el centeno sembrado en luna vieja sólo daría paja.

\section{LAS CUARENTENAS}

El tiempo cristiano es lineal, progresivo. El tiempo litúrgico, por el contrario, es cíclico. El tiempo lineal trata de armonizarlo todo mientras que el cíclico admite sin ambages la existencia de los contrarios y de los opuestos y los integran en tanto que tales. Los soportes simbólicos del tiempo cíclico son la luna y la vegetación estacionaria. La cuarentena representa la duración de un ciclo lunar y medio. El oso cuando sale de su refugio el 2 de febrero (primer día posible del martes de carnaval), observa la luna y regula su conducta según el aspecto del astro; si hay claro de

${ }^{4}$ F. Alonso Romero, «Los orígenes del mito de la Santa Compaña en las islas de Ons y Salvora», en C. de E. G., XXXII (1981), 285-305; E. Becoña, La samta campaña, el urco y los muertos (Coruña 1980); J. Filgueira Valverde, «Del urco al esperpento», en RDTP, XXXIII (1977), 55-60; M. Mandianes, «Os vivos diste e do outro mundo», en Grial, XXII, 84 (1984), 154-171; V. Risco, «Creencias gallegas. La procesión de las anmas y las premoniciones de muerte», en RDTP, II(1946), 380-429.

"CUADERNOS DE ESTUDIOS GALLEGOS", Tomo XLV, Fascículo 110, Santiago 1998. 
luna difere su salida hasta la luna nueva, 40 días más tarde y, por lo tanto, el carnaval no tendrá lugar hasta la luna nueva, 40 días más tarde. La luna al cambiar, crea el tiempo que no se puede comprender sin el fenómeno de la variación.

Los grandes ritmos del calendario, tal como se expresan a traves de las fiestas y de los refranes, son de cuarenta días. Estos periodos de mes y medio, en el conjunto del año, son la alternativa del carnaval y la cuaresma; en el calendario europeo hay, tambien, medias cuarentenas. Los meses solares y las semanas son imnovaciones cultas y relativamente recientes del calendario. Las almas se guían por las fases de la luna y esto explica que las fiestas instituidas en su honor se sucedan cada 40 días. Para Platón el tiempo es medido por un inmenso péndulo y en cada extremo de sus carreras se purifica. Las fiestas son el encadenamiento de su carrera y marcan sus extremos. El péndulo es lunar y se mueve por cuarentenas.

El Adviento empieza el domingo más próximo al día de San Andrés, Apóstol, el 30 de noviembre. Pero si atrasamos esta fecha hasta el 11 de noviembre, día de San Martín, hasta el 25 de diciembre, podríamos hablar de la primera cuarentena. Desde el día de la Navidad hasta el 2 de febrero, primera fecha posible del martes de carnaval, otra cuarentena. Desde ahora hasta el 22 de marzo primera fecha posible de la Pascua, otra cuarentena, y desde la Pascua de Resurrección hasta la Ascensión, otra; luego viene el tiempo de Pentecostés no divisible en cuarentenas. Septuagésima (63 días antes de Pascua), Sexagésima (8 semanas antes de Pascua) y Quinquagésima (7 semanas antes de Pascua), Miércoles de Ceniza, Cuaresma (46 días antes de Pascua), Pasión (tiempo de penitencia, ayuno y bastinencia), Pascua (cinco domingos) y Ascensión (40 días después de Pascua). La cuaresma era un tiempo de penitencia y mortificación, especialmente para los catecúmenos y los pecadores públicos, y de ayuno.

La Pascua se celebra en la primera luna llena de Primavera en recuerdo de la Resurrección del Señor; si esta luna cae en domingo, se aplaza hasta el domingo siguiente. Para los efectos se cree que la primavera empieza el 21 de marzo. La Pascua puede ser el 22 si es domingo y luna llena. La fecha más tardía posible de la primera luna llena de primavera es el 18 de abril; si cae en domingo, la Pascua se retrasa al 25 de del mismo mes: ocurrirá en el año 2038. La Pascua es por definición la pri- 
mera luna llena de primavera. Esta insistencia en asociar la Pascua a la luna llena se debe a que ésta denota perfección 5 .

La Vía Láctea es el camino de las almas; para que éstas lo recorran es necesario que el sol se encuentre en la Vía Láctea y que la luna se halle en una determinada fase. Estas condiciones se cumplen en el momento del carnaval. Después de su resurrección, Cristo permanece 40 días apareciéndose a los suyos hasta que la luna nueva facilita su subida a los cielos; diez días después envía su alma, en Pentecostés. «La luna no sólo es el primer muerto, sino también el primer muerto que resucita. La luna, es por lo tanto, medida del tiempo y promesa explícita de eterno retorno ${ }^{6} . »$

El origen de esta creencia podría ser el mismo texto del Génesis: el cuarto día «Dios crio los dos luceros mayores: el grande (el sol) para iluminar el día y el pequeño (la luna) para iluminar la noche» ${ }^{7}$. Dios creó, pues, un mundo perfecto al crearlo en esta primera semana con una luna llena. La luna crea el tiempo porque varía y aparece como su primera medida. La etimología en las lenguas indoeuropeas y semíticas es una serie de variaciones sobre raíces lingüísticas que significan medida ${ }^{8}$. En hebreo el mes se denomina hódes (renovación) porque se debe a la reno-

${ }^{5}$ Pedro del Río, Compendio Eclesiástico (Madrid, Imp. Real, 1790), p. 76; J. Lefort et M. F. Rouan-Auzepy, «La chronique Pascale: le temps appropié», en Le temps chtétien (Paris 1984), 451-468; DACL XIII, 2, col. 1521-1574; M. Mandianes, «Antropología del tiempo litúrgico», Rev. Española de Derecho Canónico, n. 138, 52 (1995), pp. 219 229; F. Cumont, La triple commémoration des morts, in CRAI, 1918, 278-294; G. Dagron, Troisième, neuviéme et quarantième jours dans la tradition byzantine: temps chrétien et anthropologie, en Le temps chrétien (Paris 1984), 419-430.

${ }^{6} \mathrm{G}$. Durand, Les structures anthropologiques de l'imaginaire (Paris 1984), p. 337; C. Gaignebet, El carnaval. Ensayos de mitología popular (Alta Fulla, Barcelona1984), p. 13-28; J. Amades, Astronomía y metereología populares Neotipia, Barcelona 1933; P. Saintyves, L'astrologie populaire (Paris 1937); C. Preaux, La lune dans la pensée grecque (Bruselles 1970).

${ }^{7}$ Génesis 1, 14-19. La Iglesia condena la astrología en la medida en que presupone la creencia en un determinismo por la influecnia de los astros. Cfr. DenzingerSchönmetzer, Enchiridion Symbolorum et declarationum, Barcelona 1976, n. 205.283.459.1859. 2824-2825; Catecismo de la Iglesia Católica, 2115-2117.

${ }^{8} \mathrm{C}$. Darling Buck, A dictionary of selected synonyms in the principal indo-european languages (Chicago 1949), 54-55; E. Benveniste, Le vocabulaire des institutions indoeuropéennes, 2 (Paris 1969), 123-132.

"CUADERNOS DE ESTUDIOS GALLEGOS", Tomo XLV, Fascículo 110, Santiago 1998. 
vación de la luna; en cambio, la luz del sol no experimenta ninguna renovación. El mes se refiere a la luna mientras que el año al sol'

Los doce días que aparecen en los calendarios indoeuropeos han sido reconocidos desde hace mucho tiempo como los días intercalados que miden el desajuste entre el año lunar (doce fases: 354 días) y el año solar (366 días). Para ajustar los dos hace falta jugar constantemente con estos doce días que permiten parar en el momento de los solsticios o de los equinoceos y comenzar de nuevo a partir de cero.

\section{DANZA A LA LUNA}

Estrabón dice: «Algunos dicen que los gallegos son ateos pero que los celtíveros y sus vecinos del $\mathrm{N}$. veneran un cierto dios las noches de luna y toda la familia canta y baila durante la noche delante de sus casas» ${ }^{10}$. Itaco acusaba a los priscilianistas de tener reuniones las noches a la luz de la luna ${ }^{11}$ que serían la continuidad de los bailes que los cantabros celebraban en honor de un dios desconocido y de los cantos de victoria que entonaban en las encrucijadas.

Cuando, allá por 1900, N. Tenorio recorrió las aldeas gallegas, escribió: «Existe entre los aldeanos una curiosísima costumbre, cuyo abolengo tengo por bastante primitivo. Tanto en verano como en invierno, pero más principalmente durante la primera de las dos estaciones, en las noches de luna clara y especialmente en os plenilunios, hombres y mujeres de la aldea salen de las casas a la calle a disfrutar de la claridad del astro de la noche. [Las] familias se agrupan y hacen fiesta en honor de la luna en las que danzan ombres y mujeres y cantan al son del pandero y de los conchos. Los cantares se dirigen a la luna, mezclándose en ellos episodios o quejas de amores y el baile es la clásica muiñeira del país. cada cantar termina en arrulos o atoruxos de los mozos [...] mirando hacia la luna $[\ldots]$ y dura la fiesta hasta que se acerca la luz del día» ${ }^{12}$.

${ }^{9}$ Cosmografía de un judio romano del siglo XVII (Ed. fascimil, intro. y tr. por J. M. Millán y D. Romano. Madrid-Barcelona 1954), 71.

${ }^{10}$ Estrabon, III, 4, 16

" Conc. de Zaragoza, c. IV; cfr. J. Mansi, III, p. 634.

${ }^{12}$ N. Tenorio, La aldea gallega (Cadiz, 1914), pp. 142-143.

"CUADERNOS DE ESTUDIOS GALLEGOS", Tomo XLV, Fascículo 110, Santiago 1998. 
Julio Caro Baroja cree que se trata de una danza a la luna que perdura, aún, en nuestros días. La luna era, sin duda, el dios desconocido; su nombre no se podía pronunciar A causa de los tabúes sobre este nombre, nadie hablaba de ello; este silencio sobre dios llevó a muchos a pensar que eran verdaderos ateos ${ }^{13}$. Por la zona de la Limia Alta (Orense) hasta los años sesenta se hacían los fiadeiros y a lata, reuniones para hilar y para bailar al son de una pandereta y unas latas vacías de sardinas y un par de conchas y cucharas. Los mozos lanzaban arrulos y atoruxos mirando a la luna: «Si.no había luna no se hacía; era necesaria una buena luz de luna» ${ }^{14}$.

En Loureses la noche del uno al dos de noviembre las mujeres de casa encendían al pie de un romero que crece en un rincón de la huerta que rodea la casa, tantas velas como niños murieron sin bautismo en casa porque están enterrados aquí, en el mismo lugar en donde se entierran los animales domésticos muertos y se queman las cosas viejas. El romero es una planta funeraria porque en él liban constantemente las abejas que son almiñas que vienen de la luna por eso «quien mata unha abeja tiene cien años de pena».

«La tarde del primero de noviembre, especialmente los jovenes, salen al monte a celebrar el magosto, fiesta de las castañas asadas. Buena parte de los participantes terminan borrachos; ya de noche, regresan al pueblo tiznados, «como si fueran mascaras de carnaval: bailandodo y lanzando arrulos y atoruxos ${ }^{15}$

${ }^{13}$ J. Caro, Los pueblos del norte de la Península Ibérica (San Sebastián, Txertoa, 1973), p. 138. 231-233; idem Los pueblos de España, I(Madrid, Istmo, 1981), pp. 124.

${ }_{14}$ M. Mandianes, «O fiadeiro na Limia Alta», Grial XXIV(1985), pp. 414-430.

${ }^{15}$ M. Mandianes, «El magosto», Boletín Auriense, XX-XXI(1990-91), pp. 293308. Según algunos autores cristianos Gregorio IV, fundandose en las visiones del Apocalipsis (PL, 209, 45-52), instituyó la fiesta de Todos los Santos, para celebrar y honrar a los santos, y rescatar y dedicarles el templo romano y la de los Fieles Difuntpara socorrer con las buenos obras generales a los que no tienen la dicha de ser socorridos por la oración particular». No obstante, autores modernos piensan que estas festividades de la Iglesia católica no son más que la cristianización del samahaim celta, del que el halloween de los paises anglosajones es la continuación ritual. Cfr. J. de Vries, La religion des celtes (Paris, Payot, 1963), 237-38; V. Gibert de La Vaissière, Les quatre fëtes d'ouverture de saison de l'Irlande (Thèse de doctorat de 3ème cycle. Montpellier, 1978); F. de Roux et Ch. J. Guyonvarc`h, Les fêtes celtiques (Rennes, Université-Ouest, 1995).

"CUADERNOS DE ESTUDIOS GALLEGOS", Tomo XLV, Fascículo 110, Santiago 1998. 


\section{CONCLUSIÓN}

Es difícil saber si los fideiros y a lata que hasta los años cincuenta siguieron celebrandose en Galicia eran la continuación de aquello que Estrabón y N. Tenorio dicen que era una danza en honor de la luna. Y mucho más difícil aún decir que la luna era para los celtas un dios aunque fuera desconocido o que o se podía nombrar. Si se puede afirmar que los habitantes de aquellos tiempos consideraban la luna como residencia de las almas de donde venían en forma de abeja y que, quizás, el danzar y aturuxar mirando a la luna fuera simplemente un reconocimiento y un recuerdo de los antepasados. 